\title{
Stenosis of the Iliac Arteries in a 26 Years Old Patient Producer of Cannabis but Non Consumer: Case Report and Review of Literature
}

\author{
Elfatemi B*, Bakkali T, Khloufi S, Sefiani Y, Lekehel B, Mesnaoui A, Ammar F, BensaidY
}

Service de Chirurgie vasculaire hôpital Ibn Sina Rabat

DOI: $10.36347 /$ sjmcr.2020.v08i03.023

| Received: 06.03.2020 | Accepted: 13.03.2020 | Published: 18.03.2020

*Corresponding author: Elfatemi Bouthainah

Abstract

Case Report

The vascular complications of cannabis consumption are still widely discussed and their incidence seems to be weak relative to the frequency of cannabis exposure in the global population. The main argument is a close temporal relationship between exposure and vascular complication, as well as the usual exclusion of other etiologies. There is also a significant rate of recidivism with re-exposure. However, this association does not proof any causal link between both conditions. Concerning peripheral arterial injuries, cannabis-associated arteriopathies show several epidemiological, clinical and radiological features closes to Buerger's syndrome or obliterative thromboangitis (OAT). The onset of this condition necessarily requires the consumption of cannabis. The observation of a 26 year old youth working in the production of the cannabis plant but which is not a consumer, who presents a proximal arteritis of both lower limb is reported in this article.

Keywords: Arteritis - not cannabis consumer- inhalation-chronic vascular effects-proximal atherosclerosis.

Copyright @ 2020: This is an open-access article distributed under the terms of the Creative Commons Attribution license which permits unrestricted use, distribution, and reproduction in any medium for non-commercial use (NonCommercial, or CC-BY-NC) provided the original author and source are credited.

\section{INTRODUCTION}

Cannabis is currently one of the most widespread illicit substances and its use is increasing year by year among the youth population. While the psychoactive effects have been well studied, there is still debate about the acute or chronic vascular effects of cannabis use. The available epidemiological data seem to give warning signals, but it is extremely difficult to identify cannabis use as an independent risk factor, because the etiologies of such conditions are often multifactorial. Among the most obvious confounding factors, active smoking is often present among cannabis users.

This observation has been reported because it is believed that not only cannabis use is responsible for the occurrence of peripheral arterial injuries, but also for exposure to accidental inhalation of plant dust during harvesting in cannabis growers.

\section{ObServation}

Non-smoking 26-year-old patient working in traditional cannabis production but which is not cannabis consumer and without any atherothrombotic risk factors consults for intermittent claudication of arterial origin with limitation of the walking perimeter to 150 meters. The vascular examination finds an abolition of the popliteal femoral and distal pulses of both lower limbs. An angio-scanner exam of the aorta and lower limbs was requested to objectivize a tight stenosis of the primitive iliac arteries. Regarding the young age and the absence of risk factors that could explain the occurrence and topography of the lesions, an inflammatory and thrombophilic assessment were performed and were normal.

It was decided to perform an angioplasty of the primitive iliac arteries with the insertion of stents in kissing by puncture of the two scarpas with the insertion of two introducers 7 french, after first opacification, two tight stenoses are visualized at the level of the two primitive iliac arteries (figure 1) mounted with two 0035 guides, then mounted with two steel stents mounted on $8 \mathrm{~mm}$ diameter and $60 \mathrm{~mm}$ long balloons released in kissing after inflation at 14 atmospheres (figure 2). The angiographic control was satisfactory (Figure 4). The patient was placed on double anti-platelet therapy. The evolution was marked by an improvement in the walking perimeter. The control Doppler ultrasound exam was carried out one month after objective permeable stents and absence of stenosis at other locations. 


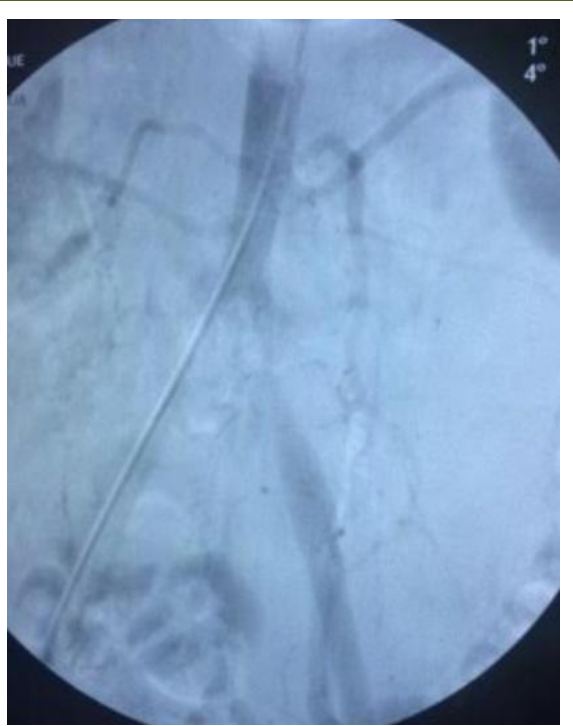

Fig-1: Angiographic image showing bilateral iliac stenosis

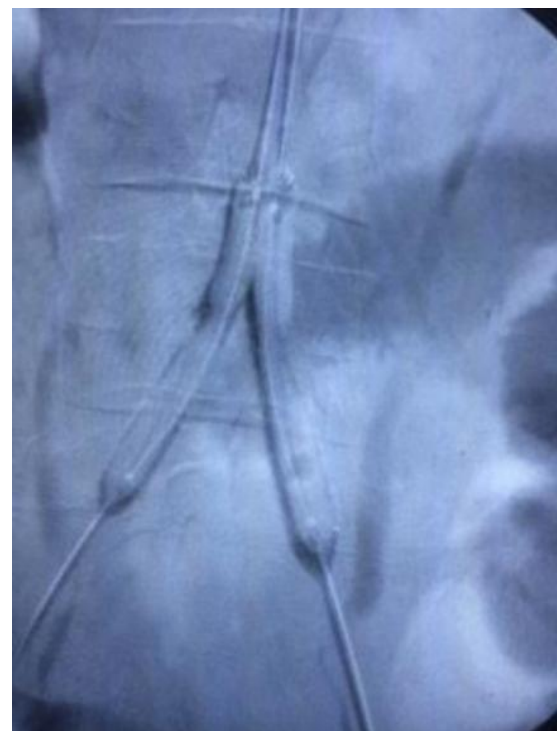

Fig-2: Release of the two stents after inflation at 14 atm

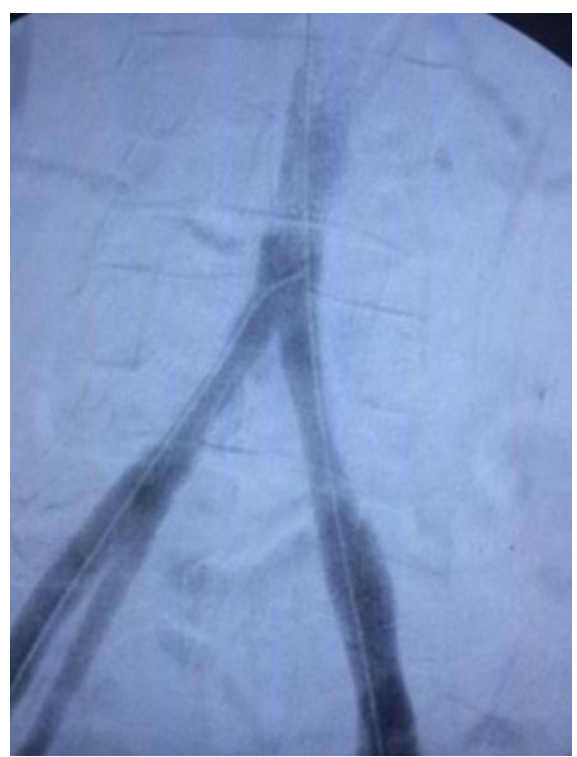

Fig-3: Angiographic control with good result

\section{DISCUSSION}

Since the end of the 1990s, cannabis has been a responsible for juvenile OAT, but is also thought to induce atherosclerosis in young people. Cannabis arteritis was first described by Sterne and Ducastaing in 1960, after studying a series of 29 men of Moroccan origin, aged 25-35 years, who were heavy cannabis consumers and who had patterns of severe distal arteriopathies [1]. The clinical exam was similar to that of Buerger's disease (obliterative thromboangiitis [OAT]), an arteriopathy of the lower limbs, beginning with claudication and progressing rapidly to trophic disorders and necrosis [1,2]. After 30 years of oblivion, probably due to the criminalization of cannabis use and the taboo associated with it [3], cannabis-related arteritis has returned to the forefront with many cases reported in the recent literature. The most comprehensive review of the literature was published by Desbois and Cacoub in 2014, who identified 80 cases of patients with cannabis-related arteritis among 20 articles published between 1960 and 2011 [4]. This additional study complements previous data [5]. Among these 80 patients, aged between 18 and 48 years, $91 \%$ of them were male. They are all regular cannabis consumers (more than one joint/day). The most common clinical presentation is, initially, bilateral lower limb involvement of the claudication type (96\%), early disappearance of distal pulses, progressing over several months and leading to necrosis of the extremities. However, less typical patterns (upper limbs, unilateral involvement, proximal vascular injury) are also possible [6, 7]. Among the associated risk factors and pathologies, we find 11 patients with Raynaud's syndrome, 11 patients with deep and superficial venous thrombosis, two diabetic patients, one hypertensive patient, and ten patients with prothrombotic mutations (seven patients with hyperhomocysteinemia, one patient with a heterozygous factor II mutation, one patient with a heterozygous factor $\mathrm{V}$ mutation, and one patient with protein $\mathrm{S}$ deficiency). Arteriography exam reveals distal lesions in the majority of cases, most often bilateral, in the form of segmental, smooth, tapered stenoses associated with collateral circulation and revascularization by vasavasorum. The angiographic abnormalities observed in OAT, although not specific, are characterized by multiple lesions of distal arterial occlusions with the development of a large network of collaterals (corkscrew image) [8]. In comparison, imaging of patients with cannabis arteriopathy shows a less developed collateral network and, occasionally, proximal atherosclerosis despite their young age. The link between OAT and tobacco consumption is well established and the role of cannabis as a precipitating factor is all the more difficult to assert since active smoking is most often present. The joint use of cannabis and nicotine could advance the age of onset of OAT, without necessarily worsening the prognosis. Compared to patients with tobacco-related arteriopathy, patients with cannabis-related arteriopathy are often younger at 
the onset of symptoms or at the time of diagnosis and present more often unilateral pain, without ischemic ulcer manifestations. In cases of persistent cannabis use, even after stopping or not smoking, the evolution of the disease is often severe and eventually requires amputation (58\% of the 80 patients studied) $[4,9,10]$.

However, total cessation of cannabis exposure, despite continued tobacco use, combined with medical and/or surgical treatment (iloprost, anti-platelet aggregation, sympatholysis, bypass, in situ thrombolysis) could, in some cases, allow regression or even healing of the lesions [9,11]. Surgical revascularization is rarely possible due to the absence of a downstream. Relapses or recurrences of symptoms have been systematically correlated with a recovery of cannabis consumption $[3,4,12-14,9,10]$ Several studies have been published on cannabis use showing its role in inducing distal arteritis in young subjects, the proximal location is rarely found in these patients. The possibility of arsenic contamination, present in some unrefined cannabis and tobacco preparations, has also been cited as a factor promoting vascular thrombosis and inflammatory arteritis via impaired endogenous NO production [15-17]. Furthermore, no case has been reported concerning the occurrence of arteritis in people working on the production of the plant as in the case of the patient previously reported. It is assumed that this lack of knowledge is due on the one hand to the fact that the producers are generally consumers of the plant and on the other hand because of the taboo and legal nature of the subject patients do not declare to be producers. The hypothesis on the mechanism of action is the accidental inhalation of plant dust at the time of harvest as probably was the case of the patient previously reported. The possibility of vascular damage by oxidative stress is also mentioned by Sarafian et al. [18]. From a histopathological point of view, very few informations are available in the literature due to the lack of conclusive anatomopathological analysis. However, the absence of atherosclerosis allows a distinction to be made between cannabis-related arteritis and other peripheral vascular disease in adults under 50 years of age. To conclude probably under-diagnosed, cannabis-related arteritis is one of the most common peripheral vascular disorders in patients under 50 years of age. Clinical, arteriographic and epidemiological approaches to OAT, or Buerger's syndrome, attempt to consider cannabis-related arteritis as a subtype of OAT [11]. Before setting the diagnosis, it is essential to exclude other etiologies (absence of cardiovascular risk, hyperviscosity, thrombophilia or other embolic pathology, elastic tissue disease, autoimmune pathology, systemic vasculitis) [19].

\section{CONCLUSION}

The causal relationship between cannabis use and various vascular complications has not been yet established. Although the incidence of vascular complications appears to be weak relative to cannabis exposure in the global population, there is likely a bias related to the lack of systematic toxicological testing or patient denial, among other factors. Through this observation, the consequence of another type of cannabis exposure in the development of distal arteritis in young subjects is reported.

\section{REFERENCE}

1. Sterne J, Ducastaing C. Les artérites du cannabis indica. Arch Mal Coeur. $1960 ; 53$ :143_7.

2. Puechal X, Fiessinger JN. Thromboangiitis obliterans or Buerger's disease: challenges for the rheumatologist. Rheumatology. 2007;46(2):192_9.

3. Constans J. Les artériopathies au cannabis. J Mal Vasc. 2002;27(1):6.

4. Desbois AC, Cacoub P. Cannabis-associated arterial disease: a literature review. Ann Vasc Surg. 2013 ;27(7):996_1005.

5. Cottencin O, Karila L, Lambert M, Arveiller C, Benyamina A, Boissonas A. Cannabis arteritis : Review of the literature. J Addict Med. 2010 ;4(4) :191_6.

6. Disdier $\mathrm{P}$, Swiader L, Jouglard J, Piquet $\mathrm{P}$, Christides C, Moulin G. Artérite du cannabis versus maladie de Léo Buerger : discussion nosologique à propos de deux nouveaux cas. Presse Med. 1999;28(2) :71_4.

7. Combemale P, Consort T, Denis-Thelis L, Estival JL, Dupin M, Kanitakis J. Cannabis arteritis. Br J Dermatol. 2005;152(1): 166_9.

8. Olin JW. Thromboangiitis obliterans (Buerger's disease). New Engl J Med. 2000;343(12):864_9.

9. Martin-Blondel G, Koskas F, Cacoub P, Sène D. Is thromboangiitis obliterans presentation influenced by cannabis addiction ? Ann Vasc Surg. 2011 ;25(4) :469_73.

10. Cazalets C, Laurat E, Cador B, Jan F, Rolland Y, Jégo P. Artériopathies du cannabis : quatre nouveaux cas. Rev Med Interne. 2003;24(2):127_30.

11. Peyrot I, Garsaud AM, Saint-Cyr I, Quitman O, Sanchez B, Quist D. Cannabis arteritis : a new case report and a review of literature. J Eur Acad Dermatol Venereol. 2007 ; 21(3) :388_91.

12. Karila L, Danel T, Coscas S, Chambon JP, Reynaud M. L'artérite progressive cannabique, un sous-type clinique de la thromboangéite oblitérante ? Presse Med. 2004 ;33(Suppl. 18) :21_3

13. Constans J, Dubiez P, Baste JC, Barcat D, Parrot F, Conri C. Cannabis arteriopathy. Presse Med. 1999 ;28(39):2154.

14. Schneider HJ, Jha S, Burnand KG. Progressive arteritis associated with cannabis use. Eur J Vasc Endovasc Surg. $1999 ; 18(4): 366 \_7$.

15. Disdier P, Granel B, Serratrice J, Constans J, Michon-Pasturel U, Hachulla E, et al. Cannabis arteritis revisited - ten new case reports. Angiology. 2001; 52(1) :1_5.

16. Noël B. Buerger disease or arsenic intoxication ? Arch Intern Med. $2001 ; 161(7): 1016 \_9$. 
17. Noël B. Regarding «Cannabis arteritis revisited ten new case report » (2001). Angiology. 2001;52(7):505_6.

18. Sarafian TA, Magallanes JAM, Shau H, Tashkin D, Roth MD. Oxidative stress produced by marijuana smoke : an adverse effect enhanced by cannabinoids. Am J Respir Cell Mol Biol. 1999;20(6):1286-93

19. Bouccin E.Complications vasculaires périphériques, cardiaques et cérébrales associées à l'utilisation du cannabis. Toxicologie analytique et clinique;2016. 